(2014). Learning Analytics for Communities of Inquiry. Journal of Learning Analytics, 1 (3), 195-198.

\title{
Learning Analytics for Communities of Inquiry
}

\author{
Vitomir Kovanovic and Dragan Gašević \\ University of Edinburgh, United Kingdom \\ Marek Hatala \\ Simon Fraser University, Canada \\ v.kovanovic@ed.ac.uk
}

\begin{abstract}
This paper describes doctoral research that focuses on the development of a learning analytics framework for inquiry-based digital learning. Building on the Community of Inquiry model (Col) - a foundation commonly used in the research and practice of digital learning and teaching - this research builds on the existing body of knowledge in two important ways. First, given that the Col model requires substantial manual coding of student discourse, its potential for guiding pedagogical interventions are limited. Thus, the first contribution is the development of a learning analytics system that automates this coding process by means of a novel textclassification algorithm that takes into the account the process nature of inquiry-based learning and the specifics of communication through asynchronous discussions. Furthermore, it is equally important to investigate how learning processes unfold over time through student interactions with information, technology, and other course participants. With this in mind, the second contribution of this research focuses on the development of analytical models that provide insight into these important aspects of inquiry-based learning.
\end{abstract}

KEYWORDS: Learning analytics, community of inquiry, quantitative content analysis, social network analysis, trace data clustering

\section{INTRODUCTION}

In distance education, the primary means of social interactions are asynchronous discussion boards. Not only do they facilitate help seeking and information sharing, but they also promote the development of learner communities and critical thinking skills (Anderson \& Dron, 2010). Over the years, many different models of online learning focusing on the use of asynchronous online discussions have been developed, with the Community of Inquiry (Col) model (Garrison, Anderson, \& Archer, 1999) being one of the most researched and adopted models. The model posits that the educational experience of members of a community of inquiry is shaped by the dimensions of 1) teaching presence, 2) social presence, and 3 ) cognitive presence. Cognitive presence is the central construct in the Col model, operationalized through four phases ranging from the initial problem conception to its resolution (Garrison et al., 1999). To support the assessment of these three dimensions, instruments for quantitative content analysis and self-reported surveys have been developed and validated.

An important challenge of the Col model relates to its practical use and the scaling up of its research. The Col model is primarily adopted using coding schemes for each of its three presences (Garrison et al., 
(2014). Learning Analytics for Communities of Inquiry. Journal of Learning Analytics, 1 (3), 195-198

1999). Given that quantitative content analysis requires significant time and manual coding work, the Col model has been primarily used for retrospection purposes and not for real-time guidance of instructional interventions. Likewise, the existing sample sizes are proportionally small, which hampers its use at large scale. Existing systems for automated coding of discussion messages developed for the Col dimensions (Corich, Hunt, \& Hunt, 2012; McKlin, Harmon, Evans, \& Jones, 2002) do not provide sufficient levels of accuracy to enable their practical application. Thus, one of the goals of this doctoral research is to develop a learning analytics system that enables more efficient message coding by means of a novel text-classification algorithm to take into account the specifics of inquiry-based learning and quantitative content analysis. Furthermore, the development of such a system entails identification of important surface-level features of online communication, which can give more detailed operationalization of the different indicators of the three dimensions of the Col model.

It is equally important to understand how the learning process in a community of inquiry unfolds through the interaction of learners with other learners, technology, and information (i.e., content). Having this in mind, in this doctoral research, we focus on two areas. First, we look at the social interactions of learners using social network analysis (SNA) to examine the role of the Col dimensions on the development of student social relationships and social capital. Second, we look the interaction of learners with technology and content in order to understand the role of student agency and educational technology use on the outcomes of student learning processes. At present, only the study by Shea et al. (2010) has examined the use of social network measures in the context of Col research. In similar manner, only a recent study by Rubin, Fernandes, and Avgerinou (2013) has looked at the relationship between students' perceived value of technological affordances and the constructs of the Col model. With the goal of providing insight into the online learning phenomena, our research focuses on examining relationships between the above-mentioned constructs and the three Col presences.

\section{METHODS}

The primary means of conducting presented research are quantitative methods and the investigation of empirical data from real-world, fully online, blended, and massive open online courses. After the literature review, the doctoral research includes collecting trace data and online discussion transcripts from several courses and manually coding the messages in accordance with the cognitive-presence coding scheme. This data is then used for the development of a text analytics system for (semi)automated message coding. Likewise, social network analysis is used to investigate the development of students' social networks and social capital, while clustering based on trace data will provide insight into student differences in terms of agency and educational technology use.

\section{RESULTS}

In the first study, we examined the use of an SVM classifier and different classification features as described by Kovanovic, Joksimovic, Gašević, and Hatala (2014a) for automating the coding of cognitive presence. While our results indicate several classes of features useful for this classification task, the 
(2014). Learning Analytics for Communities of Inquiry. Journal of Learning Analytics, 1 (3), 195-198

results also indicate the need for a classification technique that better supports the iterative, process nature of inquiry-based learning and the rules for using qualitative content analysis instruments. For example, when a message shows indicators of several phases of cognitive presence, rules of cognitive presence coding scheme state that a message should be coded to the highest exhibited phase. This is a challenge for typical text classification algorithms that use surface based-features (e.g., N-grams), as the classification is accomplished without a regard for the feature position within the message.

The study by Kovanovic, Joksimovic, Gašević, and Hatala (2014b) looked at the relationship between social presence and social network position and revealed the critical role of interactivity in student communication in the development of social capital. Likewise, the current research looking at student differences in educational technology use found six profiles associated with significant differences in the levels of cognitive presence, which are primarily formed around differences in 1) the focus on technology use (content vs. discussion), and 2 ) levels of active discussion participation.

\section{CONTRIBUTION TO LEARNING ANALTYICS}

From a practical perspective, the current research makes the following contributions: 1) it allows educational researchers and practitioners to adopt the Col model more easily, without the need to manually code messages, 2) it increases sample sizes due to faster discussion analysis procedures, 3 ) it enables development of systems for real-time monitoring of learning activities, and iv) it provides opportunities for data-driven guidance of instructional interventions, such as moderation of discussions to support learning outcomes better. Likewise, through investigating the role of the three Col presences in different socio-technological interactions, this research can provide insight into learning within communities of inquiry from a novel perspective, not currently explored in detail. Finally, this research will enable the adoption of the Col model in other learning contexts - such as MOOCs - where there are important pedagogical differences not fully addressed by current research into the Col model.

\section{REFERENCES}

Anderson, T., \& Dron, J. (2010). Three generations of distance education pedagogy. The International Review of Research in Open and Distance Learning, 12(3), 80-97.

Corich, S., Hunt, K., \& Hunt, L. (2012). Computerised content analysis for measuring critical thinking within discussion forums. Journal of E-Learning and Knowledge Society, 2(1), 47-60.

Garrison, D. R., Anderson, T., \& Archer, W. (1999). Critical inquiry in a text-based environment: Computer conferencing in higher education. The Internet and Higher Education, 2(2-3), 87-105.

Kovanovic, V., Joksimovic, S., Gašević, D., \& Hatala, M. (2014a). Automated content analysis of online discussion transcripts. Proceedings of the Workshops at the LAK 2014 Conference co-located with 4th International Conference on Learning Analytics and Knowledge (LAK 2014), March 25-28 2014, Indianapolis, IN, USA. Published online at http://ceur-ws.org/Vol-1137/.

Kovanovic, V., Joksimovic, S., Gašević, D., \& Hatala, M. (2014b). What is the source of social capital? The association between social network position and social presence in communities of inquiry. Proceedings of the Workshops at EDM 2014 Conference, co-located with 7th International 
(2014). Learning Analytics for Communities of Inquiry. Journal of Learning Analytics, 1 (3), 195-198.

Conference on Educational Data Mining (EDM 2014), July 4-7 2014, London, UK. Published online at http://ceur-ws.org/Vol-1183/.

McKlin, T., Harmon, S., Evans, W., \& Jones, M. (2002). Cognitive presence in web-based learning: A content analysis of students' online discussions. IT Forum, 60. Published online at http://itforum.coe.uga.edu/paper60/paper60.htm.

Rubin, B., Fernandes, R., \& Avgerinou, M. D. (2013). The effects of technology on the community of inquiry and satisfaction with online courses. The Internet and Higher Education, 17, 48-57.

Shea, P., Hayes, S., Vickers, J., Gozza-Cohen, M., Uzuner, S., Mehta, R., Valchova, A., \& Rangan, P. (2010). A re-examination of the community of inquiry framework: Social network and content analysis. The Internet and Higher Education, 13(1-2), 10-21. 